\title{
Unfolding the outcomes of surgical treatment of lumbar spinal stenosis-a prospective 5- and 10-year follow-up study
}

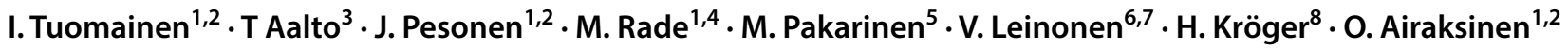

Received: 13 September 2019 / Revised: 25 February 2020 / Accepted: 13 April 2020 / Published online: 27 April 2020

(c) The Author(s) 2020

\begin{abstract}
Purpose In this prospective study, we aim to determine surgical outcomes in patients with lumbar spinal stenosis (LSS) 10 years after surgery.

Methods The study population consisted of 96 LSS patients who underwent decompressive surgery, 72 of whom participated in the 10-year follow-up. The patients completed a questionnaire preoperatively and 3 months, 5 years, and 10 years postoperatively. Outcome measures were satisfaction with the surgical outcomes, the Oswestry Disability Index (ODI), the visual analog scale (VAS), the numeric rating scale (NRS-11), and walking ability quantified in meters. Postoperative improvements at 5 and 10 years were analyzed using linear mixed models. Furthermore, comparisons between postoperative time points were made for clinical courses of pain, disability, and walking ability.

Results At the 10-year follow-up, $68 \%$ of the patients were satisfied with the surgical outcomes. All the measured outcomes showed statistically significant improvement from baseline to the 5- and 10-year follow-up. The mean VAS score was $9.8 \mathrm{~mm}$ higher at the 5-year follow-up and $7.8 \mathrm{~mm}$ at the 10-year follow-up compared to the 3-month follow-up point. Similarly, the mean ODI was $4.8 \%$ higher at the 10 -year follow-up compared to the 3 -month follow-up point.

Conclusion This study reports the clinical course of pain, disability, and walking distance after LSS surgery with the 10-year follow-up. Based on our study results, patients with LSS could expect to have positive effects of their back surgery up to 10 years. However, minor worsening in pain and disability may occur and one-fourth of the patients may need a reoperation during the 10-year follow-up period.
\end{abstract}

Keywords Lumbar spinal stenosis $\cdot$ Surgery $\cdot$ Decompression $\cdot 10$-year follow-up

\section{Introduction}

Lumbar spinal stenosis (LSS) is a leading cause of low back surgery in patients older than 65 years [1], for whom the overall surgical hospitalization rate has grown in the last decade [2]. LSS is a complex clinical syndrome mainly

I. Tuomainen

iina.tuomainen@uef.fi

1 Department of Physical and Rehabilitation Medicine, Kuopio University Hospital, PL 100, 70029 KYS Kuopio, Finland

2 Department of Surgery (Incl. Physiatry), Institute of Clinical Medicine, University of Eastern Finland, Kuopio, Finland

3 Medical Center Ikioma, Mikkeli, Finland

4 Faculty of Medicine, Orthopaedic and Rehabilitation Hospital "Prim. Dr.Martin Horvat", Josip Juraj Strossmayer University of Osijek, Osijek, Croatia caused by degenerative changes and commonly diagnosed in patients with symptoms related to a narrowing of the lumbar spinal canal seen in imaging studies [3]. However, significant associations between radiological findings and the degree of severity of clinical symptoms have rarely been found [4].

5 Department of Psychiatry, Kuopio University Hospital, University of Eastern Finland, Kuopio, Finland

6 Department of Neurosurgery, Institute of Clinical Medicine-Neurosurgery, Kuopio University Hospital, , University of Eastern Finland, Kuopio, Finland

7 Unit of Clinical Neuroscience, Neurosurgery, Medical Research Center, Oulu University Hospital, University of Oulu, Oulu, Finland

8 Department of Orthopaedics and Traumatology, Kuopio University Hospital and Kuopio Musculoskeletal Research Unit, University of Eastern Finland, Kuopio, Finland 
The most indicative clinical finding for symptomatic LSS is the presence of neurogenic claudication with improvement of symptoms while patients are bending forward, or sitting. Other related findings, such as low back, buttock, and/or lumbopelvic pain, are easily confused with other related conditions [5]. The first line of treatment in LSS is usually conservative [3]. If the conservative treatment fails to lead to an improvement in symptoms in 3 to 6 months, surgical treatment can be considered as an option for symptom relief [6]. Invasive therapies are considered when neurogenic claudication is present with positive findings from diagnostic imaging [3]. Surgery has been shown to provide better outcomes for at least 4 years in terms of disability and pain with a narrowing of the benefits over time compared with conservative treatment [6-8].

In their meta-analysis, Fritsch et al. [9] concluded that patients who underwent surgery for LSS experienced the most substantial symptom relief in the first 3 months, and that some improvements could still occur at up to 5 years. Furthermore, Fekete et al. [10] showed that surgical outcome achieved after 1 year persisted stable up to 5-year follow-up also in patients with spinal stenosis. Despite this, the longterm benefits of surgical treatment compared to conservative treatment are uncertain [11], and only limited data are available from prospective long-term studies investigating surgical outcomes in patients with LSS. Consequently, the aim of this prospective study was to describe long-term benefits of surgical treatment of LSS and fill the gap of insufficient outcome results beyond 5 years.

\section{Materials and methods}

\section{Study population}

The original study population was selected from LSS patients being treated at Kuopio University Hospital, Kuopio, Finland, between 2001 and 2004. Selection for surgery was carried out either at the department of orthopedics or at the department of neurosurgery, with 102 LSS patients meeting the inclusion criteria for the current study at the baseline. The inclusion criteria were as follows: (1) presence of severe pain in the back, buttocks, or lower extremities, with radiographic proof (computed tomography (CT), magnetic resonance imaging (MRI), or rhizography) of compression of the cauda equina or exiting nerve roots linked to degenerative changes (ligamentum flavum, facet joints, osteophytes, and/ or disk material) and (2) the surgeon's judgment that the patient had clinically significant, degenerative LSS as the main diagnosis, indicative of a need for operative treatment. Additionally, all the patients showed a history of insufficient responses to conservative treatment for several months before undergoing clinical evaluation for degenerative LSS requiring operative treatment. A previous spine surgery and coexisting disk herniation were not considered exclusion criteria if LSS was confirmed as the main reason for the surgery. However, patients with only low back pain were not included.

An urgent or emergency spinal surgery preventing recruitment, cognitive impairment prohibiting completion of the questionnaires or other failures in cooperation, and the presence of metallic instrumentation particles in the body preventing the radiological investigation were the exclusion criteria [12]. Follow-up data at all three follow-up points (3 months, 5 years, and 10 years) were missing for two patients, and 4 patients had missing measure for mean dural sac area at most stenotic level, bringing the final sample size to 96. A flowchart illustrating the patients' flow during follow-up periods is shown in Fig. 1, with patients' demographics being presented in Table 1. Ethical approval was granted by the Kuopio University Research Ethics Board.

\section{Study intervention and reoperations}

The operating surgeons filled in a surgical intervention form after every surgery. Missing data were filled in from surgery reports in the medical charts. All the patients had either open or microscopic decompression of the affected level(s) (i.e., laminotomy, hemilaminectomy, or laminectomy, with undercutting facetectomy). Nineteen patients had an additional fusion, two of them with instrumentation. The indication for additional lumbar fusion was concomitant spondylolisthesis [13]. Reoperations and other major operations after the study intervention were evaluated retrospectively from medical charts in patients who responded after 5-year follow-up. Postoperative medical charts during the follow-up time were not available in 7 cases.

Study population was divided in two groups according to type of operation (fusion or decompression alone) and type of stenosis (central and lateral stenosis or lateral stenosis only). Moreover, study group was divided in two groups according to levels of decompression ( 1 and 2 or 3 ) and mean dural sac area at most stenotic level. Mean dural sac area was evaluated through the borders of the dural sac, which were manually traced on the axial image showing the smallest cross-sectional area upon visual examination. Patients were divided into two groups: (1) patients with dural sac area less than $75 \mathrm{~mm}^{2}$ and (2) patients with dural sac area equal to or greater than $75 \mathrm{~mm}^{2}[14,15]$. The surgical interventions are described in more detail in Table 2.

\section{Outcome measures}

Surgical outcomes were collected using self-reported assessment methods with the primary outcome measure being overall satisfaction with surgical outcomes. The secondary 
Fig. 1 Flowchart illustrating the study population's progress during the follow-up periods

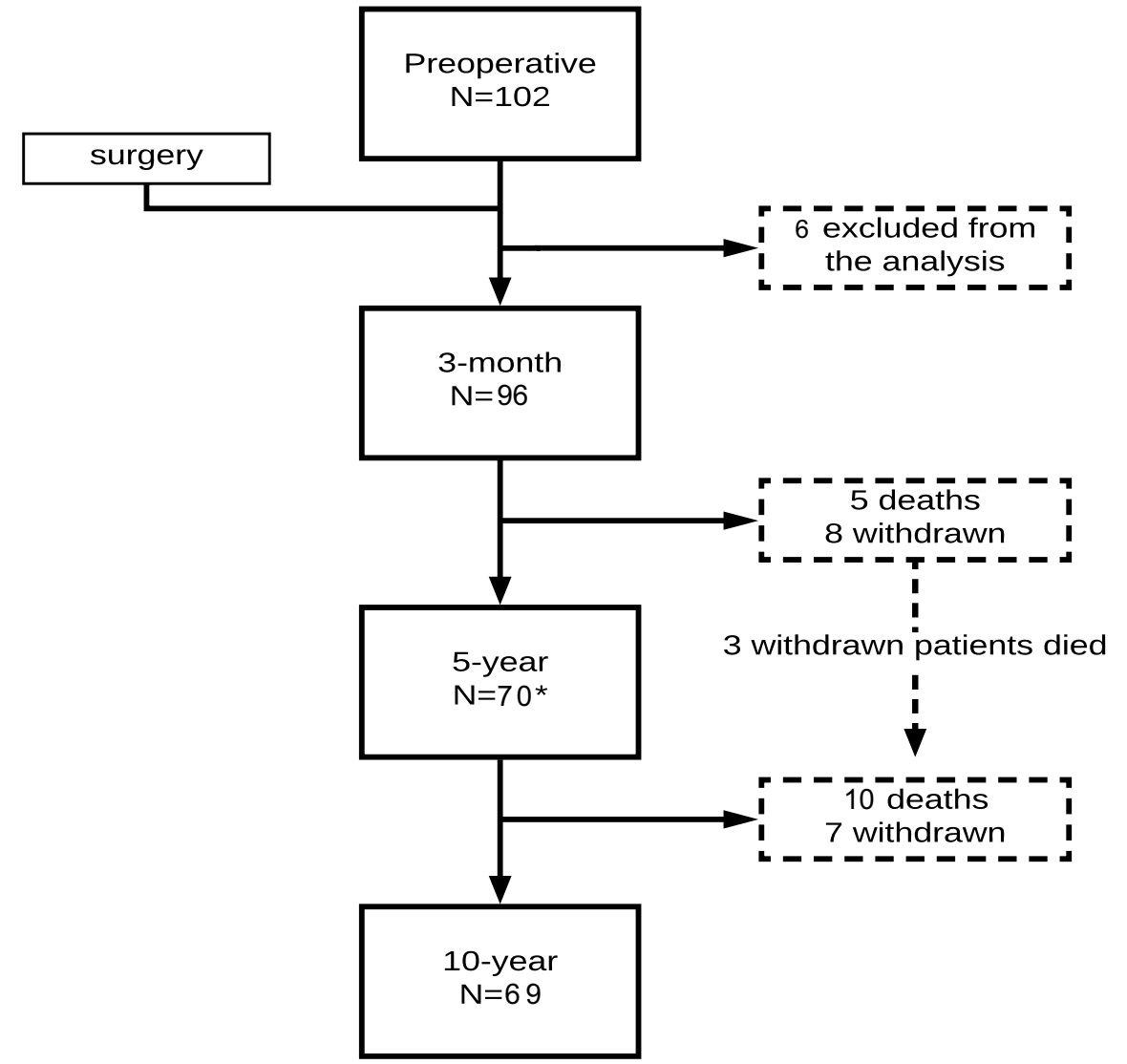

*13 patients have missing data at 5-year follow-up

Table 1 Patients' demographics at baseline $(n=96)$ and 3-month, 5-year, and 10-year follow-ups

\begin{tabular}{lllll}
\hline Follow-up point & Baseline $(n=96)$ & 3 months $(n=96)$ & 5 years $(n=70)$ & 10 years $(n=69)$ \\
\hline Age: mean (SD) & $61.6(11.2)$ & $62.1(11.1)$ & $67.4(11.3)$ & $68.5(9.8)$ \\
Gender: female (\%) & $59 \%$ & $59 \%$ & $67 \%$ & $64 \%$ \\
ODI: mean (SD) & $43.6(15.3)$ & $27.1(18.7)$ & $28.7(18.0)$ & $29.8(20.8)$ \\
VAS overall: mean (SD) & $55.2(27.0)$ & $26.0(22.3)$ & $35.4(27.8)$ & $33.4(28.1)$ \\
LBP NRS-11: mean (SD) & $4.2(2.6)$ & $1.9(2.4)$ & $1.9(2.3)$ & $2.2(2.5)$ \\
LP NRS-11: mean (SD) & $6.4(2.6)$ & $3.1(2.7)$ & $3.3(2.8)$ & $3.2(2.6)$ \\
Walking ability: median (min; max) & 900 & 2000 & 1500 & $2000(0 ; 10,000)$ \\
& $(10 ; 10,000)$ & $(20 ; 20,000)$ & $(10 ; 15,000)$ & $5.6(3.7)$ \\
Comorbidities: mean (SD) & $5.5(3.2)$ & $6.4(3.5)$ & $4.4(2.4)$ \\
\hline
\end{tabular}

$O D I$ Oswestry Disability Index, VAS visual analog scale, $N R S$-11 numeric rating scale, $L B P$ Low back pain at rest, $L P$ leg pain while walking, $S D$ standard deviation

outcome measures were functional disability, pain (such as overall pain, low back pain at rest, and leg pain while walking), and walking ability. The patients completed the detailed questionnaires before surgery and at follow-ups at 3 months, 5 years, and 10 years after the intervention.
Satisfaction with the surgical outcome was evaluated by the specific question: "How satisfied are you with the surgical outcomes?". Patients were considered satisfied with the surgical outcome if their reply was either 3, "condition has been totally cured," or 2, "condition has considerably 
Table 2 Baseline demographics of the study population and character of the surgical treatment

\begin{tabular}{|c|c|c|}
\hline & All study patients $(n=96)$ & $\begin{array}{l}\text { Patients who } \\
\text { respondent after10 } \\
\text { years } \\
(n=69)\end{array}$ \\
\hline \multicolumn{3}{|l|}{ Type of stenosis } \\
\hline Central stenosis and Lateral stenosis & $79(82 \%)$ & $56(81 \%)$ \\
\hline Only lateral stenosis & $17(18 \%)$ & $13(19 \%)$ \\
\hline Mean dural sac area at most stenotic level & $68.6 \mathrm{~mm}^{2}$ & $68.0 \mathrm{~mm}^{2}$ \\
\hline Less than $75 \mathrm{~mm}^{2}$ & 64 & 46 \\
\hline $75 \mathrm{~mm}^{2}$ or more & 32 & 23 \\
\hline \multicolumn{3}{|l|}{ Level of decompression } \\
\hline One level & 58 & $46(67 \%)$ \\
\hline Two levels & 34 & $19(28 \%)$ \\
\hline Three levels & 8 & $4(6 \%)$ \\
\hline Spondylolisthesis & $23(24 \%)$ & $18(26 \%)$ \\
\hline L1-L2 & 0 & 0 \\
\hline L2-L3 & 0 & 0 \\
\hline L3-L4 & 6 & 4 \\
\hline L4-L5 & 16 & 13 \\
\hline L5-S1 & 1 & 1 \\
\hline Fusions performed & $18(19 \%)$ & $16(23 \%)$ \\
\hline Single level & 16 & 14 \\
\hline Two levels & 2 & 2 \\
\hline Extirpation of concomitant disk herniation & 7 & $4(6 \%)$ \\
\hline L2-L3 & 1 & 0 \\
\hline L3-L4 & 1 & 0 \\
\hline L4-L5 & 4 & 3 \\
\hline L5-S1 & 1 & 1 \\
\hline
\end{tabular}

improved" on a seven-point scale from -3 to 3 . Other reply options are presented in Fig. 3.

Subjectively assessed disability was measured by the validated Finnish version of the Oswestry Disability Index (ODI, 0-100\%) [16]. A visual analog scale (VAS, 0-100 mm) was used to describe the patients' current overall pain intensity [17]. Low back pain at rest (LBP) and leg pain while walking (LP), both during the preceding week, were separately assessed with a numeric rating scale ranging from 0 to 10 [numeric rating scale (NRS-11)] [18]. In addition, selfreported walking distance in meters (continuous scale) was also evaluated and included in the analysis. Furthermore, comorbidities were evaluated using the Work Ability Index (WAI) [19], in which the number of current diseases or injuries diagnosed by a physician was recorded.

\section{Statistical analysis}

Comparisons between two independent groups were made using Student's $t$ test and the Mann-Whitney test if necessitated by data normality values. The distribution of the data was determined using histograms and QQ-plots. Categorical variables were evaluated using the Chi-square test.
McNemar's test was used to evaluate satisfaction with the surgical outcome between two follow-up time points.

Due to the availability of longitudinal data, linear mixed models were used to evaluate the changes in outcomes (ODI, VAS, LBP, LP, and walking ability) over time. To evaluate the surgical outcomes of disability, pain scores, and walking ability, the analysis included outcome pairwise comparisons between the baseline and the 5- and 10-year follow-up points. Moreover, to evaluate the postoperative clinical course of disability, pain scores, and walking ability, the analysis included outcome pairwise comparisons between the 3-month and 5-year and 10-year points, as well as between the 5-year and 10-year points. Analyses were adjusted for type of operation, type of stenosis, level of stenosis operated, and the mean dural sac area at the most stenotic level. Time and adjusted variables were set as a fixed factor, and unstructured covariance was used for repeated measures. The assumption of a normal distribution was visually checked from the residuals. Missing values were assumed to be completely random. Statistical analysis was performed using SPSS (version 25.0, SPSS/Chicago, IL, USA). 


\section{Results}

Of initial population, 15 patients (16\%) died and there were $12(13 \%)$ dropout patients at the 10-year follow-up. Thus, there was an overall participation rate of $72 \%$ at the 10-year follow-up, with dropout patients being significantly older and showing more comorbidities at baseline than other patients. However, other pre- or postoperative variables showed no statistically significant differences between the dropout and the follow-up patient groups (Table 3).

During the 10-year follow-up period, one or more reoperations were performed on 21 patients (reoperation rate $=25 \%$ ). Of these, three patients underwent two reoperations and one patient underwent three reoperations, resulting in 28 reoperations during the follow-up period. The reoperations are described in more detail in Fig. 2. An emergency operation was performed in six cases $(21 \%$ of all reoperations), with the indication for emergency surgery being disk herniation in four cases (intolerable pain $n=3$, cauda equina syndrome $n=1$ ), synovial cyst and stenosis in one case (intractable pain), and posterior element hypertrophy and myelopathy (Th12-L1) in one case. Reoperated patients were found to be younger at baseline, but other baseline characteristics showed no statistically significant differences between groups (Table 4).

During the 10-year follow-up period, $25 \%$ of patients $(n=24)$ underwent hip or knee replacement surgery, and $2 \%(n=2)$ underwent surgery due to peripheral atherosclerosis. However, outcome measures did not show any significant differences between reoperation and no-reoperation groups in a cross-sectional analysis at 5- and 10-year follow-up times (Table 5).

In this study, $68 \%$ of the patients were satisfied with the surgical outcomes after 5 and 10 years. The distribution of the responses can be seen in Fig. 3. Between postoperative time points, no statistical differences were found, as seen in Table 6.

In subgroup analyses, patients who had decompression in 2 or 3 levels had higher leg pain at 10-year follow-up when compared to patients with 1-level decompression. However, no further significant differences were found between the subgroups (Table 7). In the linear mixed model, all the outcome measures showed statistically significant improvements at the 5- and 10-year follow-up times when compared with preoperative variables (for all, $p<0.05$ ). Figure 4 shows the histograms of outcome measures at the different time points. On further analysis, the mean ODI values showed a statistically significant deterioration at the 10-year followup when compared with data from the 3-month follow-up $(p=0.040)$. Mean VAS values increased during the 5-year $(p=0.003)$ and 10-year follow-up periods $(p=0.030)$ when compared with the 3-month follow-up. However, the ODI and VAS scores did not show significant differences between the 5-year and 10-year follow-ups. In addition, other outcome variables (LPB, LP, and walking ability) remained stable during all the follow-up time, and no statistically significant difference was found between the follow-up points. Minor worsening in low back and leg pain scores was seen after 3 months, but the differences between postoperative time points were not statistically significant.

\section{Discussion}

In this study, we described the surgical outcome of decompressive surgery in patients with LSS, along with clinical course of disability, painful symptoms, and walking distance during the 10-year follow-up period. We found that $68 \%$ of the study patients were satisfied with the achieved results 5 years and 10 years after surgery. Decompressive
Table 3 Comparison of the study group characteristics at baseline between 10-year follow-up and dropout patient groups

\begin{tabular}{llll}
\hline & $\begin{array}{l}\text { Follow-up patients } \\
(N=69)\end{array}$ & $\begin{array}{l}\text { Dropout patients* } \\
(N=27)\end{array}$ & $p$ value \\
\hline Age: mean (SD) & $58.0(9.8)$ & $70.9(9.5)$ & 0.000 \\
Gender: women (\%) & $63.8 \%$ & $48.1 \%$ & 0.161 \\
ODI (\%): mean (SD) & $42.5(15.6)$ & $46.4(14.4)$ & 0.270 \\
VAS overall (mm): mean (SD) & $56.6(25.7)$ & $51.3(30.5)$ & 0.468 \\
LBP NRS-11 (0-10): mean (SD) & $4.2(2.7)$ & $4.3(2.5)$ & 0.957 \\
LP NRS-11 (0-10): mean (SD) & $6.3(2.7)$ & $6.9(2.3)$ & 0.386 \\
Walking distance (m): median (min; max) & $1000(20 ; 10,000)$ & $500(10 ; 3400)$ & 0.258 \\
Comorbidities: mean (SD) & $5.0(2.8)$ & $6.8(3.7)$ & 0.037 \\
Satisfaction at 3 months (scale -3 to 3): & $2(-2,3)$ & $2(-1,3)$ & 0.732 \\
$\quad$ median (min, max) & & & \\
\hline
\end{tabular}

$O D I$ Oswestry Disability Index, $V A S$ visual analog scale, $N R S-11$ numeric rating scale, $L B P$ low back pain at rest, $L P$ leg pain while walking, $S D$ standard deviation

*16 patients died during the 10 -year follow-up period 
Fig. 2 Characteristics of reoperations during the 10 -year follow-up
Table 4 Patients' baseline demographics according to status of reoperation

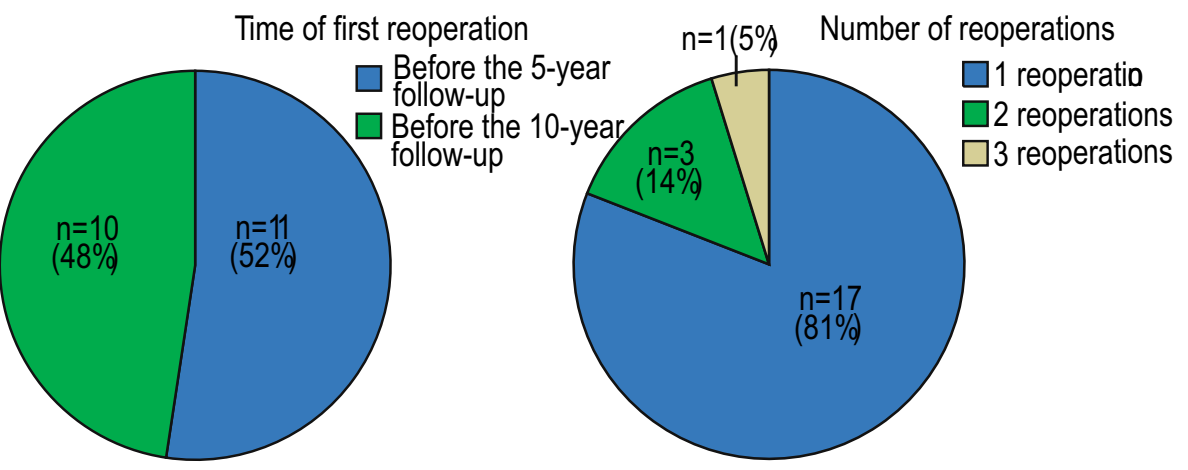

Number of levels operated

Segment operated

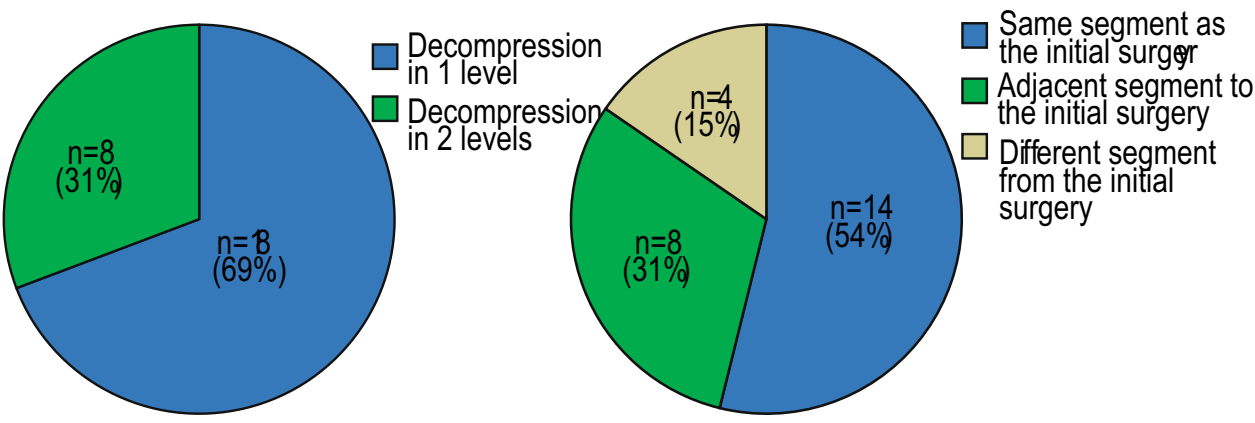

Fusion performed $(n \neq 5$

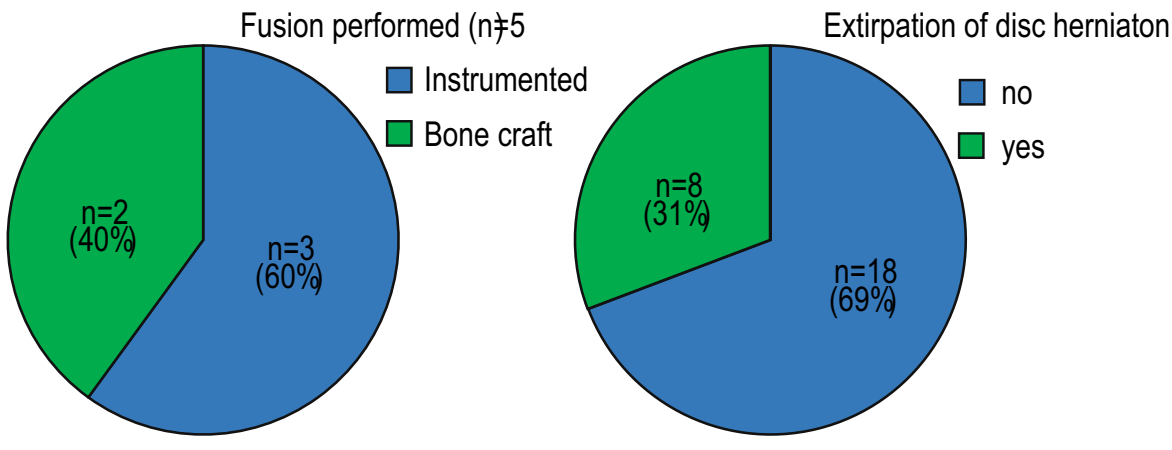

Extirpation of disc herniaton

\begin{tabular}{llll}
\hline & Reoperation $(n=21)$ & No reoperation $(n=62)$ & $p$ value \\
\hline Age: mean (SD) & $56.1(12.4)$ & $62.4(10.4)$ & 0.026 \\
Gender: women (\%) & $47.6 \%$ & $66.1 \%$ & 0.194 \\
ODI (\%): mean (SD) & $47.6(13.3)$ & $42.2(15.2)$ & 0.154 \\
VAS (mm): mean (SD) & $57.0(23.4)$ & $56.3(27.1)$ & 0.925 \\
LBP NRS-11 (0-10): mean (SD) & $4.1(2.2)$ & $3.9(2.8)$ & 0.630 \\
LP NRS-11 (0-10): mean (SD) & $5.9(2.6)$ & $6.6(2.6)$ & 0.190 \\
$\quad$ Walking distance in meters: median & $1000(20 ; 5000)$ & $500(20 ; 10,000)$ & 0.788 \\
$\quad$ (min; max) & & & \\
Comorbidities: mean (SD) & $5.5(2.9)$ & $5.1(3.0)$ & 0.508 \\
\hline
\end{tabular}

$O D I$ Oswestry Disability Index, VAS visual analog scale, $N R S$-11 numeric rating scale, $L B P$ low back pain at rest, $L P$ leg pain while walking, $S D$ standard deviation surgery seems to provide significant improvement in pain, disability, and walking distance even at 10 years after surgery. On the other hand, our study showed approximately one-fourth of the studied patients underwent reoperation before the 10-year follow-up. Furthermore, overall pain and disability showed a minor worsening after 3 months during extended follow-up period. 
Table 5 Outcome measures at the 5-year and 10-year follow-ups according to status of reoperation

\begin{tabular}{|c|c|c|c|}
\hline & Reoperation & No reoperation & $p$ value \\
\hline \multicolumn{4}{|c|}{ ODI $(\%)$ : mean $(\mathrm{SD})$} \\
\hline 5-year & $32.6(14.3)$ & $27.6(18.9)$ & 0.332 \\
\hline 10-year & $36.7(16.7)$ & $27.4(21.7)$ & 0.051 \\
\hline \multicolumn{4}{|c|}{ VAS (mm): mean (SD) } \\
\hline 5-year & $34.4(23.5)$ & $35.8(29.3)$ & 0.936 \\
\hline 10-year & $34.4(24.4)$ & $33.0(29.6)$ & 0.583 \\
\hline \multicolumn{4}{|c|}{ LBP NRS-11 (0-10): mean (SD) } \\
\hline 5 -year & $2.1(2.0)$ & $1.9(2.4)$ & 0.443 \\
\hline 10-year & $2.4(2.3)$ & $2.1(2.6)$ & 0.416 \\
\hline \multicolumn{4}{|c|}{ LP NRS-11 (0-10): mean (SD) } \\
\hline 5-year & $3.0(2.2)$ & $3.4(2.9)$ & 0.864 \\
\hline 10-year & $3.5(2.6)$ & $3.0(2.7)$ & 0.469 \\
\hline \multicolumn{4}{|c|}{ Walking distance $(\mathrm{m})$ : median $(\min ; \max )$} \\
\hline 5-year & $1750(500 ; 9000)$ & $1350(10 ; 15,000)$ & 0.301 \\
\hline 10-year & $1750(0 ; 8000)$ & $2000(0 ; 10,000)$ & 0.499 \\
\hline \multicolumn{4}{|c|}{ Satisfaction with the outcome (scale -3 to 3 ): median (min; $\max$ ) } \\
\hline 5-year & $2(-2 ; 2)$ & $2(-3 ; 3)$ & 0.161 \\
\hline 10-year & $2(-2 ; 3)$ & $2(-3 ; 3)$ & 0.065 \\
\hline
\end{tabular}

ODI Oswestry Disability Index, VAS visual analog scale, $N R S-11$ numeric rating scale, $L B P$ low back pain at rest, $L P$ leg pain while walking, $S D$ standard deviation
The satisfaction rate at 10 years corresponds to the rate reported in our earlier studies, showing a $66 \%$ satisfaction rate with the results of surgery at the 3-month follow-up [20]. Hence, even though the benefits of surgery were seen to decline after 3 months, patients were still satisfied with the results of surgery. Moreover, previous long-term followup studies have also reported satisfaction rates of 55-78\% $[8,21]$. The main goal of surgical treatment in LSS is to decompress the neural structures in the spinal canal or in the neural foramina [5] and thereby improve a patient's disability and walking ability and reduce painful symptoms. However, patient satisfaction with the surgical outcome is also an important outcome measure in order to evaluate surgical outcomes extensively in the long term, which describes most accurately the link between patients' experiences and expectations of the treatment [22]. Furthermore, a study by Parai et. al. [23] suggested that patients' global assessment of pain improvement after surgery can be an efficient tool to measure a successful outcome of degenerative lumbar spinal surgery.

The tendency of increased satisfaction with the surgical outcome over time despite the relative increase in overall pain and disability values is of particular interest. This is in line with the results of our previous study with a 5-year follow-up, which demonstrated that satisfaction was higher at the 5-year than at the 3-month follow-up points among patients with a higher sense of coherence [24]. The

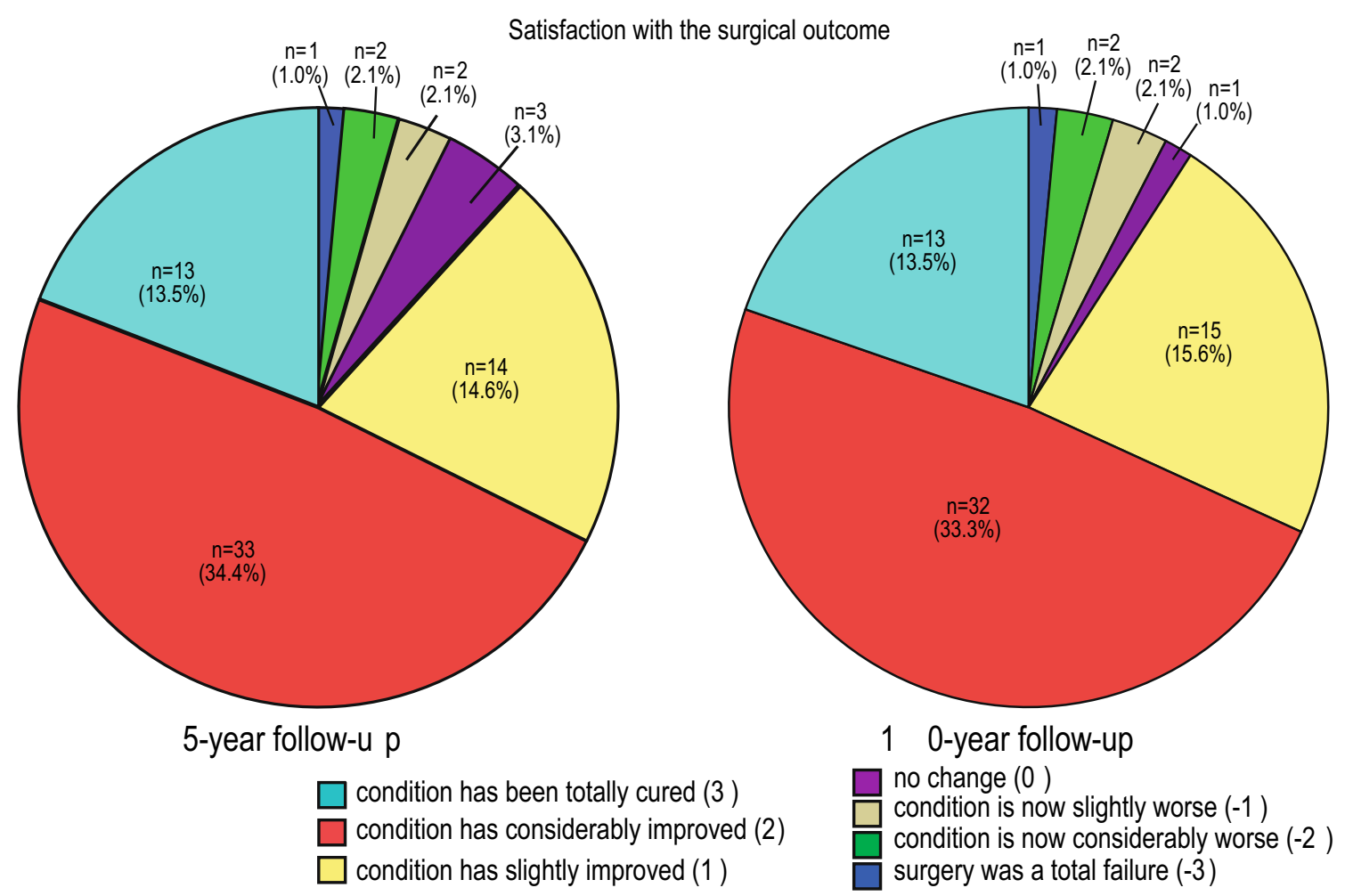

Fig. 3 Distribution of responses to the question "How satisfied are you with the surgical outcomes?" 
Table 6 Satisfaction with the surgical outcome according to postoperative follow-up time points

\begin{tabular}{lll}
\hline & 5-year satisfied & 5-year dissatisfied \\
\hline 3-month satisfied & 38 & 9 \\
3-month dissatisfied & 8 & 11 \\
& 10 -year satisfied & 10 -year dissatisfied \\
3-month satisfied & 30 & 13 \\
3-month dissatisfied & 15 & 7 \\
5-year satisfied & 10 -year satisfied & 10 -year dissatisfied \\
5-year dissatisfied & 30 & 4 \\
\hline
\end{tabular}

McNemar's test for all three time points, $p>0.05$

improvement in satisfaction could be explained by better adjustment to the chronic disease and its symptoms with increasing age. This might be due to the higher sense of coherence [25] or to other psychological factors related to better coping in later life [26].

In this study, all outcome measures (ODI, VAS, LBP, LP, and walking distance) showed significant improvements at up to 10 years; however, patients experienced more overall pain and disability at 10 years when compared to 3 months after the surgery. Even though ODI and VAS scores deteriorated after 3 months in our study population, study subjects reported only minimal changes in LBP and LP symptoms and walking distance at up to 10 years. However, the greatest improvement in disability and pain scores occurred within 3 months after surgery. This is in line with the findings of the previous studies, which also described a considerable reduction in pain and disability in the first 3 months, and that an improving trend in outcomes remains almost stable up to 5 years after surgery $[9,10]$. However, previous studies have not included the clinical course of walking ability nor the satisfaction rate with the surgical outcome, and the follow-up time has only been up to 5 years.

Our findings concerning LP and LBP are in line with those of Mannion et al. [21] in which LP and LBP intensity seemed to remain stable during a 5-year follow-up after LSS surgery. In addition, in their meta-analysis by Fritch et al. [9], they describe only a slight increase in LBP after 3 months. However, a study by Anjarwalla et al. [27] showed a deteriorating trend in leg and back pain in a 5-year followup; however, they did not perform analyses between postoperative time points.

One reason why overall pain (VAS) and disability (ODI) increased while walking ability, LBP at rest, and LP while walking mostly remained constant in our study population may be the long 10-year follow-up period. This inevitably leads to other comorbidities and musculoskeletal disorders related to aging. In this study group, $24 \%$ of the patients underwent hip or knee replacement surgery, but only $2 \%$ had surgery due to peripheral atherosclerosis. Moreover, previous studies have also shown a deterioration of the benefits of surgery after 4 years when compared to conservative treatment [6-8]. A meta-analysis by Zaina et al. [11] concluded that no recommendations can be made about the best treatment choices in patients with LSS. However, in extended follow-up studies of LSS surgery, patients have experienced improvements in pain and disability compared to the baseline [9, 21,27]. Based on our results, after surgical treatment patients with LSS can experience improvements in disability and pain scores, as well as walking ability, even up to 10 years after the surgery, even though some worsening in symptoms may occur. Fekete et al. [10] concluded that surgical outcomes remained constant after greatest improvement up to 5 years. Based on our study results, after 5 years symptoms and satisfaction with the surgical outcome remain fairly stable up to 10 years. However, further studies are needed to investigate postoperative outcome results of LSS surgery over the 10-year follow-up.

There are some limitations to this study. First, the aging of the study subjects and the occurrence of musculoskeletal comorbidities may play a role in the natural course of functional ability and painful symptoms, so we cannot conclude that our study results are a direct consequence of the initial surgery. Moreover, $25 \%$ of the study subjects underwent reoperation procedures during the follow-up period, which is in accordance with findings in other long-term investigations [8,21]. Second, the loss of study subjects due to deaths and other reasons, and differences in baseline variables (age and comorbidities) might bias the results. Third, the possible effects of the subjectivity of the outcome measures employed need to be considered as a limitation. Fourth, lack of non-surgical arm precludes to evaluate the effect of surgical treatment exclusively. Furthermore, heterogeneity of the data has an impact on the generalization of data; nevertheless, the results were adjusted with these variables.

One strength of this study is the high participation rate despite the long follow-up period. Another strength is its reporting of the clinical course of pain, walking distance, and disability, even up to 10 years. Moreover, the outcome measures used (ODI and VAS) are validated patient-reported tools in spinal research and regarded as useful in measuring patients' disability and pain [28]. In addition, our study setting was pragmatic, so our findings are directly applicable to clinical settings. This study provides important information for clinicians as well as patients with LSS undergoing surgical treatment. 
Table 7 Surgical outcome measures at different time points according to type of operation, type of stenosis, levels of decompression and mean dural sac area at most stenotic level

\begin{tabular}{|c|c|c|c|c|}
\hline & Preoperative & 3-month & 5-year & 10-year \\
\hline \multicolumn{5}{|l|}{ ODI (\%): mean (SD) } \\
\hline \multicolumn{5}{|l|}{ Type of operation } \\
\hline Fusion & $43.5(13.4)$ & $22.9(16.1)$ & $29.4(21.4)$ & $27.7(21.7)$ \\
\hline Decompression alone & $43.6(15.8)$ & $28.1(19.2)$ & $28.5(17.1)$ & $30.5(20.7)$ \\
\hline$p$ value & 0.975 & 0.345 & 0.898 & 0.536 \\
\hline \multicolumn{5}{|l|}{ Type of stenosis } \\
\hline Central and lateral & $44.4(16.3)$ & $27.9(19.2)$ & $30.5(17.9)$ & $31.9(21.3)$ \\
\hline Lateral only & $39.9(9.4)$ & $23.5(15.8)$ & $20.2(16.3)$ & $21.1(16.8)$ \\
\hline$p$ value & 0.278 & 0.477 & 0.066 & 0.105 \\
\hline \multicolumn{5}{|l|}{ Levels of decompression } \\
\hline 1 level & $41.9(15.8)$ & $24.8(17.6)$ & $26.1(17.5)$ & $27.7(21.2)$ \\
\hline 2 or 3 levels & $46.2(14.4)$ & $30.5(19.9)$ & $33.1(18.3)$ & $34.0(19.7)$ \\
\hline$p$ value & 0.179 & 0.175 & 0.082 & 0.190 \\
\hline \multicolumn{5}{|c|}{ Mean dural sac area at the most stenotic level } \\
\hline Less than $75 \mathrm{~mm}^{2}$ & $43.8(16.2)$ & $26.6(17.8)$ & $30.7(18.5)$ & $31.8(20.1)$ \\
\hline $75 \mathrm{~mm}^{2}$ or more & $43.2(13.6)$ & $28.0(20.6)$ & $24.3(16.3)$ & $25.9(22.2)$ \\
\hline$p$ value & 0.575 & 0.876 & 0.201 & 0.219 \\
\hline \multicolumn{5}{|l|}{ VAS (mm): mean (SD) } \\
\hline \multicolumn{5}{|l|}{ Type of operation } \\
\hline Fusion & $58.2(28.4)$ & $21.2(20.4)$ & $38.6(30.0)$ & $35.7(29.2)$ \\
\hline Decompression alone & $54.5(26.8)$ & $27.1(22.7)$ & $34.5(27.3)$ & $32.6(28.0)$ \\
\hline$p$ value & 0.511 & 0.372 & 0.661 & 0.575 \\
\hline \multicolumn{5}{|l|}{ Type of stenosis } \\
\hline Central and lateral & $54.3(28.8)$ & $26.5(22.9)$ & $36.9(27.3)$ & $34.7(28.7)$ \\
\hline Lateral only & $59.2(16.9)$ & $23.4(19.7)$ & $29.1(29.9)$ & $27.2(25.7)$ \\
\hline$p$ value & 0.705 & 0.655 & 0.336 & 0.567 \\
\hline \multicolumn{5}{|l|}{ Levels of decompression } \\
\hline 1 level & $56.8(24.5)$ & $23.6(19.7)$ & $36.8(29.3)$ & $30.1(28.5)$ \\
\hline 2 or 3 levels & $52.7(30.7)$ & $29.5(25.6)$ & $33.1(25.4)$ & $40.1(26.8)$ \\
\hline$p$ value & 0.677 & 0.502 & 0.748 & 0.197 \\
\hline \multicolumn{5}{|c|}{ Mean dural sac area at the most stenotic level } \\
\hline Less than $75 \mathrm{~mm}^{2}$ & $53.9(28.5)$ & $26.3(22.9)$ & $37.3(27.6)$ & $34.5(27.9)$ \\
\hline $75 \mathrm{~mm}^{2}$ or more & $57.7(24.1)$ & $25.4(21.3)$ & $31.1(28.4)$ & $31.1(29.1)$ \\
\hline$p$ value & 0.652 & 0.892 & 0.409 & 0.524 \\
\hline \multicolumn{5}{|c|}{ LBP NRS-11 (0-10): mean (SD) } \\
\hline \multicolumn{5}{|l|}{ Type of operation } \\
\hline Fusion & $3.4(2.6)$ & $1.2(1.4)$ & $1.7(2.2)$ & $1.9(2.7)$ \\
\hline Decompression alone & $4.4(2.6)$ & $2.0(2.5)$ & $2.0(2.3)$ & $2.2(2.5)$ \\
\hline$p$-value & 0.192 & 0.638 & 0.655 & 0.420 \\
\hline \multicolumn{5}{|l|}{ Type of stenosis } \\
\hline Central and lateral & $4.1(2.6)$ & $1.8(2.4)$ & $2.0(2.2)$ & $2.3(2.5)$ \\
\hline Lateral only & $4.6(2.8)$ & $1.9(2.3)$ & $1.6(2.7)$ & $1.8(2.5)$ \\
\hline$p$ value & 0.494 & 0.775 & 0.325 & 0.474 \\
\hline \multicolumn{5}{|l|}{ Levels of decompression } \\
\hline 1 level & $4.3(2.6)$ & $1.8(2.2)$ & $2.1(2.5)$ & $1.8(2.3)$ \\
\hline 2 or 3 levels & $4.1(2.8)$ & $2.0(2.6)$ & $1.7(1.9)$ & $2.9(2.7)$ \\
\hline$p$-value & 0.572 & 0.860 & 0.876 & 0.076 \\
\hline \multicolumn{5}{|c|}{ Mean dural sac area at the most stenotic level } \\
\hline Less than $75 \mathrm{~cm}$ & $4.1(2.7)$ & $1.8(2.2)$ & $1.8(2.1)$ & $2.2(2.5)$ \\
\hline $75-100 \mathrm{~mm}$ & $4.4(2.6)$ & $1.9(2.7)$ & $2.2(2.7)$ & $2.1(2.4)$ \\
\hline$p$-value & 0.587 & 0.800 & 0.987 & 0.866 \\
\hline
\end{tabular}


Table 7 (continued)

\begin{tabular}{|c|c|c|c|c|}
\hline & Preoperative & 3-month & 5-year & 10-year \\
\hline \multicolumn{5}{|c|}{ LP NRS-11 (0-10): mean (SD) } \\
\hline \multicolumn{5}{|l|}{ Type of operation } \\
\hline Fusion & $6.9(2.7)$ & $2.4(2.5)$ & $3.5(2.8)$ & $3.8(3.0)$ \\
\hline Decompression alone & $6.3(2.6)$ & $3.2(2.8)$ & $3.3(2.8)$ & $2.9(2.5)$ \\
\hline$p$ value & 0.266 & 0.256 & 0.782 & 0.324 \\
\hline \multicolumn{5}{|l|}{ Type of stenosis } \\
\hline Central and lateral & $6.4(2.7)$ & $3.1(2.7)$ & $3.5(2.7)$ & $3.3(2.6)$ \\
\hline Lateral only & $6.4(2.1)$ & $2.8(2.9)$ & $2.7(3.1)$ & $2.6(2.7)$ \\
\hline$p$ value & 0.652 & 0.573 & 0.310 & 0.383 \\
\hline \multicolumn{5}{|l|}{ Level of decompression } \\
\hline 1 level & $6.3(2.6)$ & $3.0(2.7)$ & $3.2(2.8)$ & $2.6(2.6)$ \\
\hline 2 or 3 levels & $6.6(2.7)$ & $3.2(2.8)$ & $3.5(2.7)$ & $4.1(2.5)$ \\
\hline$p$-value & 0.473 & 0.879 & 0.604 & 0.015 \\
\hline \multicolumn{5}{|c|}{ Mean dural sac area at the most stenotic level } \\
\hline Less than $75 \mathrm{~mm}^{2}$ & $6.4(2.8)$ & $2.9(2.6)$ & $3.2(2.7)$ & $3.4(2.7)$ \\
\hline $75 \mathrm{~mm}^{2}$ or more & $6.6(2.2)$ & $3.4(3.0)$ & $3.6(2.9)$ & $2.6(2.4)$ \\
\hline$p$ value & 0.908 & 0.465 & 0.673 & 0.291 \\
\hline \multicolumn{5}{|c|}{ Walking distance $(\mathrm{m})$ : median $(\min ; \max )$} \\
\hline \multicolumn{5}{|l|}{ Type of operation } \\
\hline Fusion & $1500[100 ; 10,000]$ & $2000[200 ; 20,000]$ & $2000[10 ; 10,000]$ & $1500[15 ; 9999]$ \\
\hline Decompression alone & $650[10 ; 9999]$ & $1500[20 ; 9999]$ & $1350[30 ; 15,000]$ & $2000[0 ; 10,000]$ \\
\hline$p$-value & 0.233 & 0.444 & 0.858 & 0.946 \\
\hline \multicolumn{5}{|l|}{ Type of stenosis } \\
\hline Central and lateral & $500[10 ; 10,000]$ & $1500[20 ; 20,000]$ & $1200[10 ; 10,000]$ & $1500[0 ; 9999]$ \\
\hline Lateral only & $1000[100 ; 5000]$ & $3000[300 ; 9000]$ & $2000[50 ; 15,000]$ & $2000[200 ; 10,000]$ \\
\hline$p$ value & 0.412 & 0.094 & 0.253 & 0.300 \\
\hline \multicolumn{5}{|l|}{ Levels of decompression } \\
\hline 1 level & $1000[10 ; 10,000]$ & $2000[20 ; 20,000]$ & $2000[10 ; 15,000]$ & $2000[0 ; 10,000]$ \\
\hline 2 or 3 levels & $500[20 ; 9999]$ & 1250 [200; 9999] & $1050[30 ; 9999]$ & $1000[0 ; 9999]$ \\
\hline$p$ value & 0.472 & 0.183 & 0.461 & 0.330 \\
\hline \multicolumn{5}{|c|}{ Mean dural sac area at the most stenotic level } \\
\hline Less than $75 \mathrm{~mm}^{2}$ & $1000[20 ; 10,000]$ & $1750[100 ; 20,000]$ & $1500[10 ; 10,000]$ & $\begin{array}{l}1500 \\
{[0 ; 9999]}\end{array}$ \\
\hline $75 \mathrm{~mm}^{2}$ or more & $\begin{array}{l}500 \\
{[10 ; 5000]}\end{array}$ & $\begin{array}{l}2000 \\
{[20 ; 9999]}\end{array}$ & $\begin{array}{l}1750 \\
{[50 ; 15,000]}\end{array}$ & $2000[0 ; 10,000]$ \\
\hline$p$ value & 0.737 & 0.988 & 0.958 & 0.568 \\
\hline
\end{tabular}

ODI Oswestry Disability Index, VAS visual analog scale, $N R S-11$ numeric rating scale, $L B P$ Low back pain at rest, $L P$ leg pain while walking, $S D$ standard deviation

\section{Conclusion}

In conclusion, this study shows the clinical course of pain, disability, and walking distance along with a high satisfaction rate with surgical outcomes of LSS in a 10 -year follow-up. Based on our study results, patients with LSS could expect to have positive effects of their back surgery up to 10 years. However, minor worsening in pain and disability may occur and one-fourth of the patients may need a reoperation during the 10 -year follow-up period. 

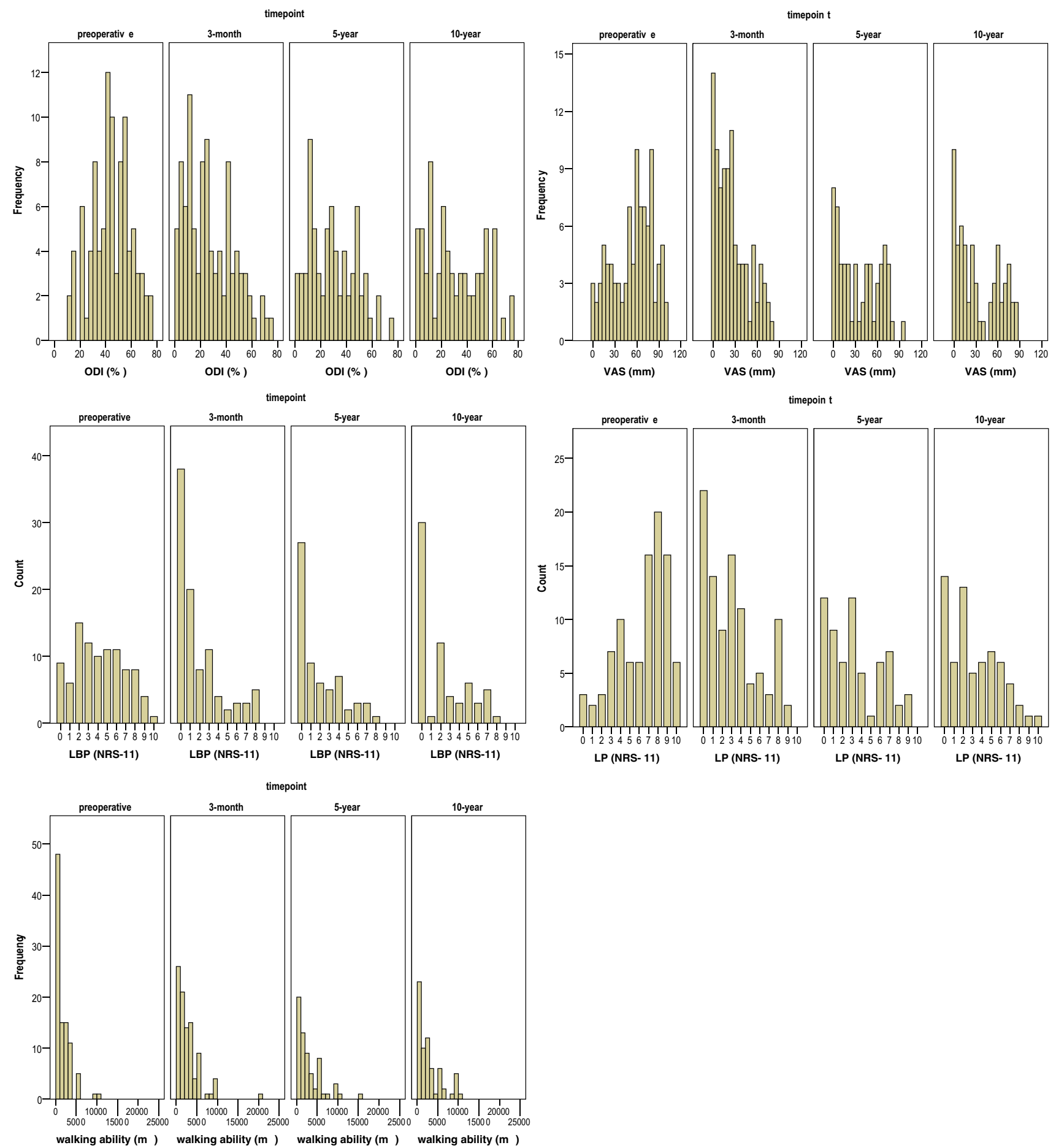

Fig. 4 The histograms of a disability (ODI), b overall pain (VAS), $\mathbf{c}$ low back pain at rest (LBP), $\mathbf{d}$ leg pain while walking (LP), and e walking ability

Acknowledgements Open access funding provided by University of Eastern Finland (UEF) including Kuopio University Hospital. The first author acknowledges the Research Committee of the Kuopio University Hospital Catchment Area for the State Research Funding and the Finnish Cultural Foundation Grant, North Savo Regional Fund.

\section{Compliance with ethical standards}

Conflict of interest The authors declare that they have no conflict of interest. 
Open Access This article is licensed under a Creative Commons Attribution 4.0 International License, which permits use, sharing, adaptation, distribution and reproduction in any medium or format, as long as you give appropriate credit to the original author(s) and the source, provide a link to the Creative Commons licence, and indicate if changes were made. The images or other third party material in this article are included in the article's Creative Commons licence, unless indicated otherwise in a credit line to the material. If material is not included in the article's Creative Commons licence and your intended use is not permitted by statutory regulation or exceeds the permitted use, you will need to obtain permission directly from the copyright holder. To view a copy of this licence, visit http://creativecommons.org/licenses/by/4.0/.

\section{References}

1. Ciol MA, Deyo RA, Howell E, Kreif S (1996) An assessment of surgery for spinal stenosis: time trends, geographic variations, complications, and reoperations. J Am Geriatr Soc 44:285-290. https://doi.org/10.1111/j.1532-5415.1996.tb00915.x

2. Skolasky RL, Maggard AM, Thorpe RJ et al (2013) United States Hospital admissions for lumbar spinal stenosis. Spine 38:22722278. https://doi.org/10.1097/BRS.0b013e3182a3d392

3. Genevay S, Atlas SJ (2010) Lumbar spinal stenosis. Best Pract Res Clin Rheumatol 24:253-265. https://doi.org/10.1016/j. berh.2009.11.001

4. Weber C, Giannadakis C, Rao V et al (2016) Is there an association between radiological severity of lumbar spinal stenosis and disability, pain, or surgical outcome? Spine 41:E78-E83. https:// doi.org/10.1097/BRS.0000000000001166

5. Katz JN, Harris MB (2008) Lumbar spinal stenosis. N Engl J Med 358:818-825. https://doi.org/10.1056/NEJMcp0708097

6. Kovacs FM, Urrútia G, Alarcón JD (2011) Surgery versus conservative treatment for symptomatic lumbar spinal stenosis. Spine 36:E1335-E1351. https://doi.org/10.1097/BRS.0b013e31820c97b 1

7. Lurie JD, Tosteson TD, Tosteson A et al (2015) Long-term outcomes of lumbar spinal stenosis: eight-year results of the spine patient outcomes research trial (SPORT). Spine 40:63-76. https ://doi.org/10.1097/BRS.0000000000000731

8. Atlas SJ, Keller RB, Wu YA et al (2005) Long-term outcomes of surgical and nonsurgical management of lumbar spinal stenosis: $8-10$ year results from the maine lumbar spine study. Spine 30:936-943. https://doi.org/10.1097/01.brs.0000158953.57966.c0

9. Fritsch CG, Ferreira ML, Maher CG et al (2017) The clinical course of pain and disability following surgery for spinal stenosis: a systematic review and meta-analysis of cohort studies. Eur Spine J 26:324-335. https://doi.org/10.1007/s00586-016-4668-0

10. Fekete TF, Loibl M, Jeszenszky D et al (2018) How does patientrated outcome change over time following the surgical treatment of degenerative disorders of the thoracolumbar spine? Eur Spine J 27:700-708. https://doi.org/10.1007/s00586-017-5358-2

11. Zaina F, Tomkins-Lane C, Carragee E, Negrini S (2016) Surgical versus non-surgical treatment for lumbar spinal stenosis. Cochrane Database Syst Rev. https://doi.org/10.1002/14651858.CD010264. pub2

12. Sinikallio S, Aalto T, Airaksinen O et al (2006) Depression and associated factors in patients with lumbar spinal stenosis. Disabil Rehabil 28:415-422. https://doi.org/10.1080/096382805001924 62

13. Aalto TJ, Leinonen V, Herno A et al (2011) Postoperative rehabilitation does not improve functional outcome in lumbar spinal stenosis: a prospective study with 2-year postoperative followup. Eur Spine J 20:1331-1340. https://doi.org/10.1007/s0058 6-011-1781-y

14. Kuittinen P, Sipola P, Aalto TJ et al (2014) Correlation of lateral stenosis in MRI with symptoms, walking capacity and EMG findings in patients with surgically confirmed lateral lumbar spinal canal stenosis. BMC Musculoskelet Disord 15:247. https://doi. org/10.1186/1471-2474-15-247

15. Schönström N, Lindahl S, Willén J, Hansson T (1989) Dynamic changes in the dimensions of the lumbar spinal canal: an experimental study in vitro. J Orthop Res 7:115-121. https://doi. org/10.1002/jor.1100070116

16. Fairbank JC, Pynsent PB (2000) The Oswestry disability index. Spine 25:2940-52 (discussion 2952)

17. Price DD, McGrath PA, Rafii A, Buckingham B (1983) The validation of visual analogue scales as ratio scale measures for chronic and experimental pain. Pain 17:45-56

18. Breivik EK, Björnsson GA, Skovlund E (2000) A comparison of pain rating scales by sampling from clinical trial data. Clin J Pain $16: 22-28$

19. Tuomi K, Ilmarinen J, Jahkola A, Katajarinne L TA (1998) Work ability index. 2nd ed. Helsinki: Finnish Institute of Occupational Health. Occupational Health Care 19

20. Sinikallio S, Aalto T, Airaksinen O et al (2007) Lumbar spinal stenosis patients are satisfied with short-term results of surgery-younger age, symptom severity, disability and depression decrease satisfaction. Disabil Rehabil 29:537-544. https://doi. org/10.1080/09638280600902646

21. Mannion AF, Denzler R, Dvorak J, Grob D (2010) Five-year outcome of surgical decompression of the lumbar spine without fusion. Eur Spine J 19:1883-1891. https://doi.org/10.1007/s0058 6-010-1535-2

22. Bederman SS (2013) Commentary: Patient satisfaction in spinal surgery: should we be addressing customer service or health improvement? Spine J 13:507-509. https://doi.org/10.1016/j.spine e.2013.02.031

23. Parai C, Hägg O, Lind B, Brisby H (2018) The value of patient global assessment in lumbar spine surgery: an evaluation based on more than 90,000 patients. Eur Spine J 27:554-563. https:// doi.org/10.1007/s00586-017-5331-0

24. Pakarinen M, Sinikallio S, Koivumaa-Honkanen H et al (2017) Low sense of coherence during postoperative recovery is associated with a poorer lumbar spinal stenosis - surgical outcome: A 5-year follow-up study. J Health Psychol 22:347-355. https://doi. org/10.1177/1359105315603471

25. Nilsson KW, Leppert J, Simonsson B, Starrin B (2010) Sense of coherence and psychological well-being: improvement with age. J Epidemiol Community Health 64:347-352. https://doi. org/10.1136/jech.2008.081174

26. Vaillant GE (2003) Mental Health. Am J Psychiatry 160:13731384. https://doi.org/10.1176/appi.ajp.160.8.1373

27. Anjarwalla NK, Brown LC, McGregor AH (2007) The outcome of spinal decompression surgery 5 years on. Eur Spine J 16:18421847. https://doi.org/10.1007/s00586-007-0393-z

28. DeVine J, Norvell DC, Ecker E et al (2011) Evaluating the correlation and responsiveness of patient-reported pain with function and quality-of-life outcomes after spine surgery. Spine 36:S69-74. https://doi.org/10.1097/BRS.0b013e31822ef6de

Publisher's Note Springer Nature remains neutral with regard to jurisdictional claims in published maps and institutional affiliations. 